\title{
Survey of Mental-Emotional Status of Junior High School Students in Bandung District, West Java Province, Indonesia
}

\section{Asep Rustandi Gojali}

Postgraduate Student Faculty of Public Health, Universitas Indonesia, Depok, Indonesia

\section{Abstract}

Mental health is important factor for health adolescent future. Mental and emotional problems of the teenager is a specific health problem, and recently not threaten adequate especially in Bandung District. The main causes of mental-emotional problems in a teenager are school environment. Screening of mental-emotional problems is very important to prevents further noticeable behavior problem. The aim of the study was to describe mental-emotional problems in Junior High School students in Bandung District. This study uses a survey with the SDQ-strengths and difficulties questionnaire, interview and Focus Group Discussion. The sample of this population is the 8th-grade students in junior high school as much as 4650 students from 10 junior high schools. The results showed that student with normal mental - emotional status as much as $85.1 \%$ and borderlines mental - emotional status as much as $11.8 \%$ and abnormal mental emotional status as much as $1.9 \%$. The student with the emotional disorder includes anxiety and depression; hyperactivity problems such as Attention Deficit Hyperactivity Disorder (ADHD) and peer problems such as bullying. Mentalemotional problems of the student should be adequate intervention. Suggested the need to conduct education, curricula modification, promote school healthcare, childparent communication, psychotherapy, and training to improve life skill competencies.

Keywords: Teenager; student;mental-emotional problem; the SDQ

\section{Introduction}

Selection and Peer-review under the responsibility of the 2 nd International Meeting of Public Health 2016 Conference Committee.

\section{G OPEN ACCESS}

Mental Health is not just the absence of illness, rather it is conceptualized as a state of well being in which the individual realizes his or her own abilities, can cope with the normal stresses of life, can work productively and fruitfully, and is able to make a contribution to his or her community (WHO 2013). Mental disorders and behavior, according to The World Health Report 2011, experienced by approximately $25 \%$ of the population at some time in their lives, mental disorders and behavioral experienced at one time by approximately $10 \%$ of the adult population and the rest are children and teens. The WHO action plan 2013-2020 on mental health assembly, is a milestone in 
acknowledging the importance of mental health well-being of entire populations (WHO 2013).

Based on the survey data collection in 2012, which carried the Health Office of West Java Province to some junior high school in West Java, obtained the data that adolescent girls junior high school age showed psychological problems ranging from anxiety, mild depression to suicidal thoughts, this is due to the demands and pressure obtained at school junior high school students from both schools and parents excessive demands (Dinas Kesehatan Provinsi Jawa Barat 2012).

Mental-emotional and behavioral disorders (MEB disorders) such as depression, behavioral problems and substance abuse among children and adolescents causes a heavy burden on the family, the nation and themselves. In addition to physical health, mental health is an important factor for the future and well-being of adolescents. Fourteen to $20 \%$ of adolescents experience mental disorders, emotional and behavioral. Eighty percent of adolescents aged 11-15 years said to have demonstrated high-risk behavior at least once in the period, as misbehave in school, substance abuse, and antisocial behavior. In one study showed that $50 \%$ of adolescents have used marijuana, $65 \%$ of teens smoke, and $82 \%$ have ever tried to use alcohol.

Adolescence is a critical period in the development cycle of a person, where at this time there were many changes, good changes in biological, psychological and social change. Phase changes are often triggered conflict between adolescents with itself and the conflict with the surrounding environment. If these conflicts can not be resolved properly then in its development can have negative impacts, especially on the maturation of teenage characters and not infrequently lead to mental disorders.

Adolescent mental health issues are not handled properly and wisely, are likely to affect the mental development of children, so in addition, to disrupt the process of learning and development emotional could also have an impact on subsequent mental health into adulthood. Increasing problems with mental disorders also have social impacts include increased levels of violence, crime, suicide, child abuse, divorce, delinquency, substances abuse, HIV/AIDS, gambling, unemployment, and others. Therefore, mental health problems in children and adolescents should be managed seriously. Early detection of these problems is very important to prevent the emergence of behavioral disorders are more pronounced in the future. This baseline data needed as evidence base data for mental health policy development programs in Bandung District.

\section{Methods}




\subsection{Design}

The study was a cross sectional design. It used mix designed: qualitative and quantitative design. Its designed describe of the mental-emotional status of students in Junior high school in Bandung District. The instrument used in this study was the SDQ (strength and difficulties questionnaire).

The Strengths and Difficulties Questionnaire (SDQ) is a brief behavioral screening questionnaire about 8-16-year-olds. The SDQ (11-17 version) is an as assessment of overall psichological functioning, as well as emotional symptoms, peer problem, hyperactivity-inattention, conduct problem and prosocial behavior (Goodman 2001). It exists in several versions to meet the needs of researchers, clinicians, and educationalists. This SDQquestionnair was validated by Child Mental Health Division (Medicine Faculty, University of Padadjaran). The Questionnaire contains 25 questions with each of the five domains such as emotional domain, peer problems domain, conduct domain, and pro-social domains. SDQ questionnaire used is a questionnaire for children aged 11-17 years in which respondents can fill in questionnaires by themselves without the help of parents or teachers.

The sample of the population is student garde 8th in junior high school in Bandung district as many 4650 students. After the questionnaire is filled, answers were scored according to their share group. Interpretation of mental-emotional problems was calculated to scoring each domain of the questionnaire SDQ. Respondents who did not fill out a questionnaire to complete would be dropped out and the research sample.

\subsection{Collecting data}

First, researchers have conducted socialization regarding the intent, purpose and how to fill out questionnaires to potential respondents. Before filling out the questionnaire the researchers gave informed consent sheets to determine the willingness of potential respondents entering the study. Students who are willing to research respondents were given 30 minutes to fill out a questionnaire.

The team conducted interviews with focus group discussions with the counselor teachers to the interpretation of the score abnormal and borderline. Furthermore, respondents were categorized as normal, borderline and abnormal then conducted with deep interviews to get a problems overview and stressors. 


\subsection{Data analysis}

Analysis of data in the form of descriptive analysis. Data processing includes editing, scoring was done manually by teachers and helped by health centers trained nurses, further scrutiny, according to criteria of the existing value such as: normally, borderline, and abnormal from each domain. After that, we use analyzed data with SPSS and excel Microsoft.

\section{Results}

The results showed that students have a total of borderline or abnormal SDQ scores more emotional symptoms assessed in SDQ similar to symptoms that include somatic symptoms of depression, unhappiness, anxiety, fear and lack of confidence.

Adolescents suffering from chronic depression can be demonstrated signs such as insomnia, very less interaction with peers, etc. What they are used for the review as before, etc. It is important that the parents recognize signs singer as soon as possible. The possibility that they would develop a tendency to suicide. Know more about understanding adolescent depression signs and causes of teen suicide.

Based on the data of research findings obtained data is that cases of adolescents with emotional disorders are quite high reached (see Figure 1). Some studies show suffered depression more women than men. There is the student with emotional disorders such as anxiety, mild depression, depression until suicide idea.

Incident of Attention deficit hyperactivity disorder (ADHD) is not significant as the statistic, but, it's one of the most common problems that affect the behavior of an adolescent teenager. This is the kind of learning disorder that is characterized by poor attention span that affects the academic performance of children. Along with learning problems, adolescents may also suffer from problems such as hyperactivity, impulsive behavior, etc. The behavior is sometimes seen as a part of adolescent behavior and is often not taken seriously by parents. However, there are ways in which parents can identify children with ADHD. If a teen has consistently scored poorly in his examinations, the reason for this can be a nuisance at the top. Also, teens who have this problem tend to be aggressive and likely to engage in antisocial behaviors like shoplifting teens, drinking, smoking, etc. Because they find it difficult to do well in school, there is a high probability that they would drop out of frustration and low self-esteem. It can also lead them to risky behavior such as smoking, drug abuse, alcoholism, etc.

Conduct disorder refers to a group of behavioral and emotional problems in youngsters. Children and adolescents with this disorder have great difficulty following rules 
and behaving in a socially acceptable way. They are often viewed by other children, adults and social agencies as "bad" or delinquent, rather than mentally ill. Many factors may contribute to a child developing conduct disorder, including brain damage, child abuse or neglect, genetic vulnerability, school failure, and traumatic life experiences.

Teenagers with true antisocial personality disorder usually have exhibited this pattern of behavior from before the age of fifteen, although the diagnosis cannot be officially made until age eighteen. Without professional help and a supportive family, they may grow up to become immature, irresponsible adults with an alarming lack of conscience.

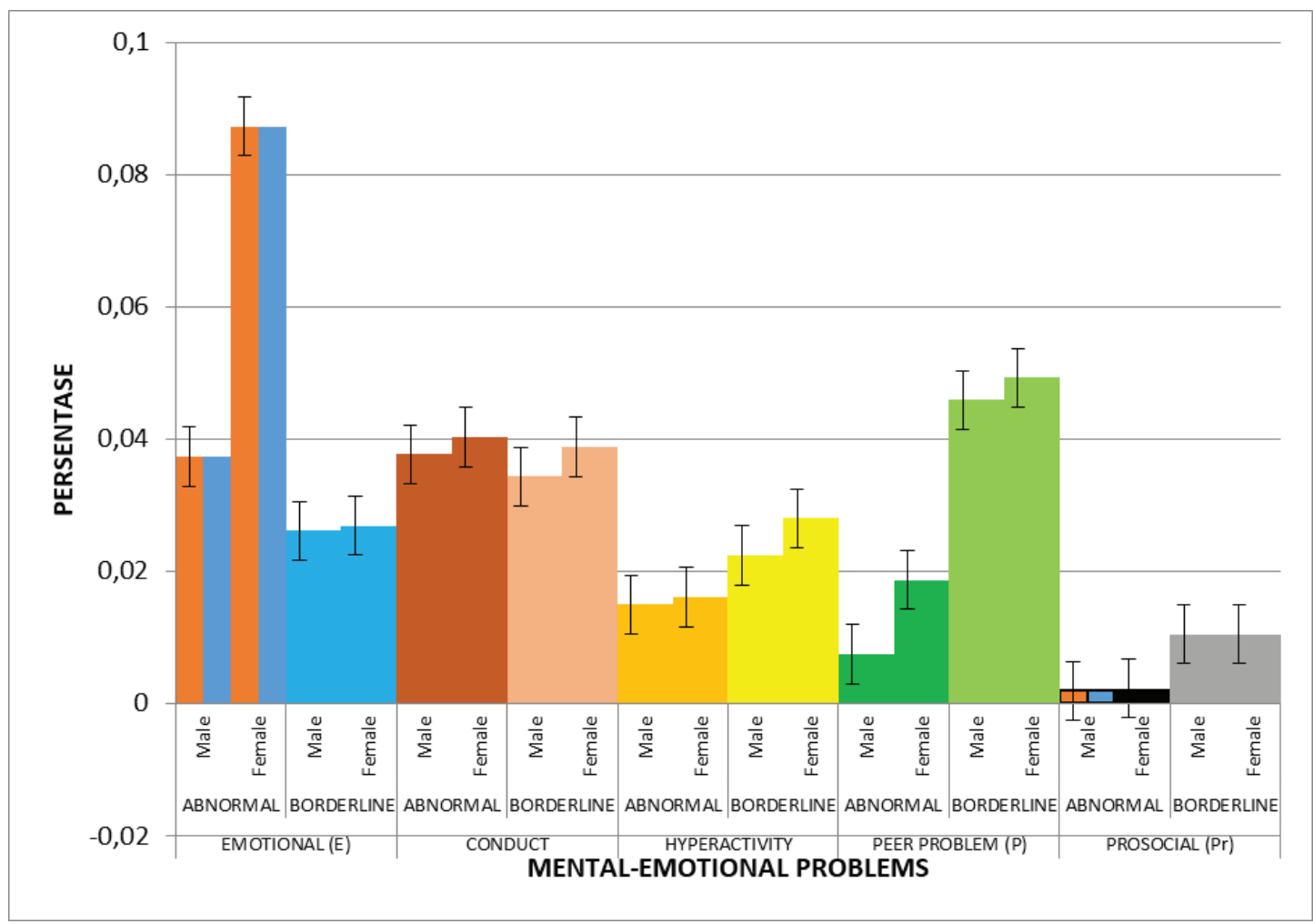

Figure 1: Mental Emotional Status of Junior High School Students in Bandung District.

\section{Discussion}

The Strengths and Difficulties Questionnaire (SDQ) is a brief behavioral screening questionnaire about 8-16-year-olds. It exists in several versions to meet the needs of researchers, clinicians, and educationalists. These preliminary findings suggest that the SDQ functions as well as the Rutter questionnaires while offering the following additional advantages: a focus on strengths as well as difficulties; better coverage of inattention, peer relationships and prosocial behavior; a shorter format; and a single form suitable for both parents and teachers, perhaps thereby increasing parent-teacher correlations. 
Many children with a conduct disorder may have coexisting conditions such as mood disorders, anxiety, post-traumatic disorder- PTSD, substance abuse, ADHD, learning problems, or thought disorders which can also be treated. Research shows that youngsters with conduct disorder are likely to have ongoing problems if they and their families do not receive early and comprehensive treatment. Without treatment, many youngsters with conduct disorder are unable to adapt to the demands of adulthood and continue to have problems with relationships and holding a job. They often break laws or behave in an antisocial manner.

Mental Health is not just the absence of illness, rather it is conceptualized as a state of well being in which the individual realizes his or her own abilities, can cope with the normal stresses of life, can work productively and fruitfully, and is able to make a contribution to his or her community. (WHO 2013). Consequently, public mental health is not just about the occurrence and prevention of mental disorders in the population, but its also concerns the promotion of mental health and well being. Thus public mental health can be defined as actions aimed at developing the mental health of populations and producing a healthy society. When setting the post-2015 development goals, promotions of population of mental health is important, mental health has vast and global wellbeing consequences.

The WHO action plan 2013-2020 on mental health assembly, is a milestone in acknowledging the importance of mental health well-being of entire populations (WHO 2013). The plans four major objectives are to strengthen effective leadership and governance for mental health; provide comprehensive, integrate, and responsive mental health and social care services in community based setting; implement strategies for promotion and prevention in mental health; and strengthen information systems, evidence and research for mental health. School is important setting for mental health promotion, through their role in helping to establish their identity, interpersonal relationships, and other transferable skills.

Activities operate under a variety of headings, not only mental health but also social and emotional learning, emotional literacy, emotional intelligence, resilience, life skills, and character educations. Positive impact includes the reduction of depression, aggression, impulsiveness, and anti-social behavior, as well as the development of proficiencies that promote mental health such as cooperation, resilience, a sense of optimism, empathy, positive and realistic self-concept. 


\section{Recommendation}

Community system-strengthening intervention focuses on developing empowering processes and building a sense of ownership and social responsibility within community members. An example: Community That Care (CTC) program, CTC intervention activates the community to implement community violent and aggression preventions systems. The strategy help community use local data on risk and protective, factors to identify risk and developt actions(Detel et al.2013).

That includes interventions that operate simultaneously at multiple ecological levels such as: in the community (e.g mobilization, media, and policy change), in the school (e.g, curricula, teaching practice); the famili (e.g training family, parenting); and the individuals (e.g social competency strategies) (Bartlette et al. 2007).

Parental education might also involve helping understand the positive impact of their monitoring of their child's behavior has been found to be superior to an adolescent only intervention in the prevention of problem behavior like risky sex and substance abuse like alcohol use and smoking. Life skills competency and education for children and adolescent needed for strengthening child personality to prevent behavior disorder (Solaeman pour et al. 2010).

\section{Acknowledgment}

This study was funding by Bandung District Health Office. I wish to thank Dr.Veranita Prandia, and the team of a child-adolescent Psychiatry Division- Padjadjaran University for validating The SDQ - Strenght and Difficulties Questionnaire. I would thank Public Health Nurse and Mental-Consult Teachers in Bandung District for helping collect and scoring data.

\section{References}

[1] Bartlette, et al. 2007. Problem Behavior in adolescent. Pediatric Nursing. Arizona:Duke University.

[2] Detel, et al. 2013. Oxford Texbook Of Global Public Health,: The Practice Of Public Health.Sixth Edition, University Of Oxford. UK

[3] Dinas Kesehatan Provinsi Jawa Barat. 2012. Laporan Case Finding Kesehatan Jiwa Anak sekolah di 10 Kabupaten/Kota tahun 2012. Dinas Kesehatan Provinsi Jawa Barat. 
[4] Goodman R.2001. The Strengths and Difficulties Questionnaire: A Research Note. Journal of Child Psychology and Psychiatry, 38, 581-586. Available from URL. http: //www.sdqinfo.org/py/sdqinfo/b0.py. Accessed 20 August 2016.

[5] Solaeman pour et al. 2010. The Role of School Health Centers in Health Care Access.and Client Outcomes. American Journal of Public Health. Vol 100. No.09. Available from URL.. Accessed 10 September 2016

[6] WHO. 2013. Draft Comprehensive Mental Health Action Plan 2013-2020. WHO: Geneva. Available from URL: http;//apps.who.int/gb/ebwha/pdf_files/WHA66/ A66_10rev1-en.pdf. Accessed 10 September 2016. 